\title{
Proportioning accuracy of foam concentrate testing in periodic control of foam fixed extinguishing systems
}

\author{
Mirosław Sobolewski ${ }^{1}$, Bernard Król ${ }^{1}$, Jakub Jakubiec ${ }^{1, *}$ and Dominika Gancarczyk ${ }^{1}$ \\ ${ }^{1}$ The Main School of Fire Service, Faculty of Fire Safety Engineering, 52/54 Slowackiego St., 01-629 \\ Warsaw, Poland
}

\begin{abstract}
The proper concentration of foam concentrate in water solution is a key factor in the effectiveness of fire-fighting foams produced using all currently used foam systems. The standard method for measuring the concentration of foaming agent, used to control the operation of the foam systems, is conductivity method. In this study, the applicability of the refractive index of the solution and the conductivity method was tested. The research found that the conductivity method can be used to determine the actual concentrations of all types of foaming agents in the solutions made from tap water, or water of similar electrical conductivity, of approx. $0.5 \div 0.8 \mathrm{mS} / \mathrm{cm}$. Conductivity meter must be equipped with temperature compensation system. Measurement uncertainty is estimated to be \pm 0.1 vol. \% under optimal conditions for this method. In the case of water with high electrical conductivity, also refractometric method gives good results. In the case of solutions made with tap water and foaming agents working concentrations of $3 \%$ and more acceptable uncertainty in the measurements provides portable digital refractometer without temperature stabilization. In other cases, obtaining sufficient accuracy requires sample temperature stabilization during the test.
\end{abstract}

\section{Introduction}

Foams are the primary agent of fighting the fire of hydrocarbon and polar liquids. They are used in the fire department operations, in both fixed fire extinguishing systems and portable and mobile extinguishers. The effectiveness of firefighting operations using foam depends on proper selection of foaming agent, efficient operation of all system components and the application of foam suitable foam application rate [1]. One of the most important information about the foam concentration included in certificate of admittance is the required concentration in the aqueous solution. Forming a solution of such concentration is a basic condition for obtaining foam of extinguishing efficiency declared by the manufacture. Therefore the proper concentration of foaming agent in water is a key factor in the effectiveness of fire-fighting foams produced from a particular foaming agent, using all currently used foam systems. Too low concentration of the foaming agent can cause a decrease or loss of extinguishing efficiency, too much concentration limits the duration of

\footnotetext{
${ }^{*}$ Corresponding author: jjakubiec@sgsp.edu.pl
} 
administration of foam at a particular store inside, too high concentration reduces administration time foam at a particular foam supply. In most cases the foam solutions are produced in the dispensing system that is dosing the foam agent concentrate into the water flowing in the system or fire lines. Correct operation of the system is essential for the proper operation of the whole system of foam, and it can be checked by measuring the concentration of foaming agent solution targeted for devices foaming agents. For example, such control carried out annually, is required by Polish Standard PN-EN 13565-2 [4].

Laboratory tests properties of foams solution and foam parameters lead to the conclusion that a small difference between the actual concentration of the solution from the assumed working concentration does not adversely affect the expansion ratio and foam stability or other important parameters of foam solution such as surface tension and the spreading coefficient in the case of AFFF foams. In most cases, it is assumed that a sufficient foam proportioning accuracy is within $\pm 10 \%$ of the set value in [1]. The technical requirements for specific types of equipment foam-adopted different requirements for accuracy foam proportioning. The technical requirements for specific types of equipment foam, adopted different requirements for accuracy foam proportioning. For example, the PN-EN 13565-1 require that the actual concentration of the solution of the foam prepared by a dispensing apparatus is not lower than a set concentration and the concentration was higher than the set value by more than $30 \%$, or one percentage point, depending on which of these values is lower [5]. Regarding to the fire fighting vehicles used in Poland it is required that installed foam agent dosing devices ensure dosage accuracy within $\pm 0,5 \%$ of the set concentration. For example, for a working concentration of $3 \%$, after setting the dispenser of $3 \%$, the actual concentration of foaming agent in the solution should be in the range from $2.5 \div 3.5 \%$ in all operating conditions of the foam system. [6].

The standard method for measuring the concentration of foaming agents, used to control the operation of the foam systems is conductivity method. It's use involves making measurements of electrical conductivity of solution flowing through the system once it is operational and reading the concentration with a predetermined calibration relationship, electrical conductivity of the solution - concentration. This relationship can usually be described with high accuracy closer to straight line. Admission to the an accurate reading off the concentration is the steepness of the calibration line. This condition is fulfilled in the case of tap water or a similar water with low conductivity and a P, FP-foaming agents, and some $\mathrm{S}$ type. In the case of industrial water or surface water and the use of AFFF and AFFF AR, a small slope of the calibration line makes it difficult to read true concentration with sufficient accuracy. Another problem is the significant influence of temperature on the electrical conductivity of the solutions. On the other hand, the advantages of the conductivity method are ease of measurements on the spot without transporting samples to the laboratory.

Other methods based on selected parameters of the solution as refractive index, dynamic viscosity, determination of chemical oxygen demand COD, changes caused by the addition of a foaming agent can also be used to measure the true concentration of solutions of foam concentrate in extinguishing systems. The condition for the practical application of these instrumental methods is the thermostatting or compensation of the influence of temperature on a given parameter. This is due to the high temperature effect on the results of measurements of electrical conductivity, refractive index or solution viscosity.

In this study two of the most commonly used methods for determining the actual foam concentrate concentration in a solution were analyzed - the conductometric method and the method of measuring the refractive index. 


\section{Measurement results and discussion}

\subsection{The methods and materials used in the study}

Instrumental studies included measurements of electrical conductivity coefficient, refractive index and coefficient of dynamic viscosity of the solutions selected foaming agents of various types - S, AFFF, AFFF-AR and FP and FFFP. The solutions were prepared by gravimetric method using analytical balance with an accuracy of $1 \mathrm{mg}$ to minimize the impact of the uncertainty of the concentration values to the measurement uncertainty of a given parameter. Taking into account the density of the foam concentrate (density measured densimeter with an accuracy of $0.01 \mathrm{~g} / \mathrm{cm}^{3}$ ) concentrations of standard solutions were converted to volumetric concentration in $\% \mathrm{v} / \mathrm{v}$.

To minimize the effect of temperature on the results, solutions temperature and the ambient temperature were controlled, so that all the solutions have the same temperature at ambient temperature. Conductivity measurements were carried CPC 551 Elmetron device compensating the effect of temperature of the solution by converting conductivity on a standard temperature of $25^{\circ} \mathrm{C}$. Measurements of refractive index were performed using two types of digital refractometer. In the case of the portable refractometer Refracto $30 \mathrm{GS}$ Mettler Toledo samples of solutions were thermostated prior to measurement at ambient temperature. Other measurements were performed digital refractometer Kyoto Electronics RA 620 with Peltier temperature control system.

Samples of foaming agents available in firefighting services in Poland were used for the measurements. The study was conducted for the solutions prepared with tap water and saltwater - prepared in the laboratory, with different $\mathrm{NaCl}$ contents.

\subsection{The use of conductivity method for tap water and saltwater}

CPC-551 conductivity meter used to measure provides accuracy of $0.5 \%$ in measuring ranges, which measured the electrical conductivity of solutions of synthetic foaming agents and $1 \%$ in the measurement range for saltwater. Measurements were performed for working concentrations (specified by the manufacturers and equal 3\%) solutions of S, AFFF, ARAFFF and FP types.

The measurement results for the solutions of synthetic agents in tap water is shown in Figure $1[10]$.
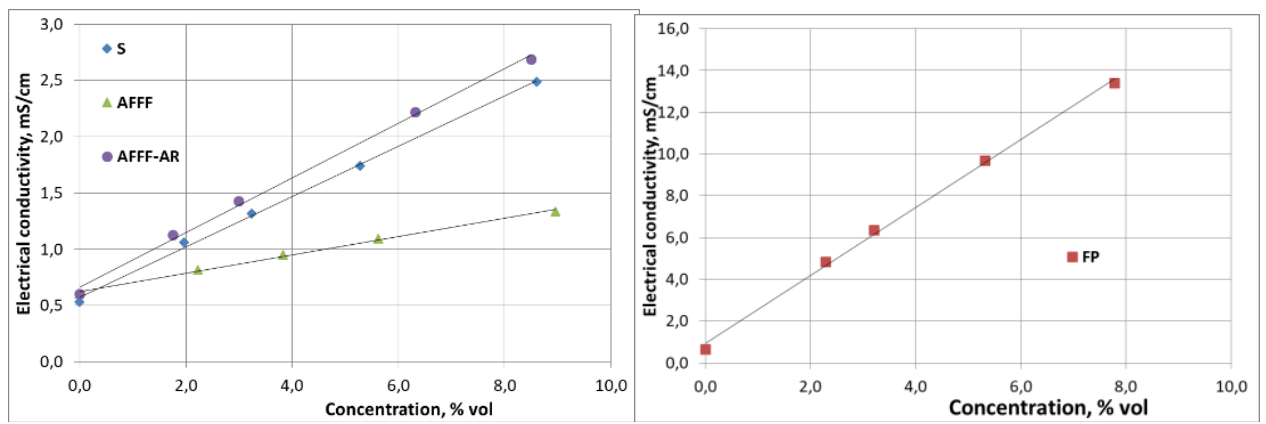

Figure 1. Electrical conductivity of S, AFFF, AFFF-AR and FP foaming agents solutions in tap water, $25^{\circ} \mathrm{C}$.

At a time when the measurements were made, electrical conductivity of the water used for the measurements varied in the range of approx. 0.55 to $0.66 \mathrm{mS} / \mathrm{cm}$. The measurement results for all testing foaming agents with high accuracy can be considered linear relationships - $\mathrm{R}^{2}$ correlation coefficients ranged from 0.997 to 0.998 . The ability to 
accurately read the concentration by measuring the electrical conductivity of the solution is greater for the investigated $\mathrm{S}$ and AFFF-AR foams, for which the derivative $\mathrm{dP} / \mathrm{dc}$ was 0.22 $\mathrm{mS} / \mathrm{cm} / \%$ and $0.24 \mathrm{mS} / \mathrm{cm} / \%$ compared to the case of $\mathrm{AFFF}$, for which $\mathrm{dP} / \mathrm{dc}=0.08$ $\mathrm{mS} / \mathrm{cm} / \%$.

Figure 1 shows the effect of additives FP foaming agent for measures of conductivity of solutions made from tap water. The impact of a protein foaming agents on the electrical conductivity of aqueous solution is much greater than in the case of synthetic, which results from the production process of protein hydrolyzer [10]. The correlation coefficient in the case of FP was 0.998. Large slope of the straight line amounting to $1.63 \mathrm{mS} / \mathrm{cm} / \%$ facilitates accurate reading off the concentration of the solution. In addition to the inclination of the calibration line for accuracy of reading (or calculate) the concentration of the solution obviously affect the correlation coefficient and the uncertainty of the measurement procedure used electrical conductivity of solutions. In the case of solutions in tap water expanded uncertainty of measurements estimated at $1 \%$ of reading.

Table 1 shows the parameters characterizing the conductivity method for determining the concentration of foaming agents in the solutions in tap water with electric conductivity approx. $0.6 \mathrm{mS} / \mathrm{cm}$ by using a conductivity meter CPC 551. Measurement uncertainty evaluated for concentration of approx. $3 \%$ for each foaming agent, and converted it into the uncertainty of reading concentration. The estimated uncertainty of measurement of the concentration of foaming agent refer not only to the very principle of measurement, but also the equipment used and the measurement procedures and should be regarded as maximum values. Those can be used to compare the various methods of measurement, but the calculation is based on the accuracy specified by the manufacturer, so it is impossible to obtain accurate measurements in practice.

The summary shows it is possible to determine, with sufficient accuracy for practical purposes, the concentration of each tested foaming agent if foam system from which the sample solution was taken for test is supplied with water close to the electrical conductivity of tap water.

For the same foaming agents, the measurements of electrical conductivity of the saline solution similar to sea water prepared from the water containing about $35 \mathrm{~g} / \mathrm{dm}^{3} \mathrm{NaCl}$, were made. A similar measurement procedures were used. The solutions for measuring the various foaming agents were performed separately performed portion of the saltwater, a somewhat different in electrical conductivity. The measurement results of electrical conductivity of solutions shown in Figure 2.

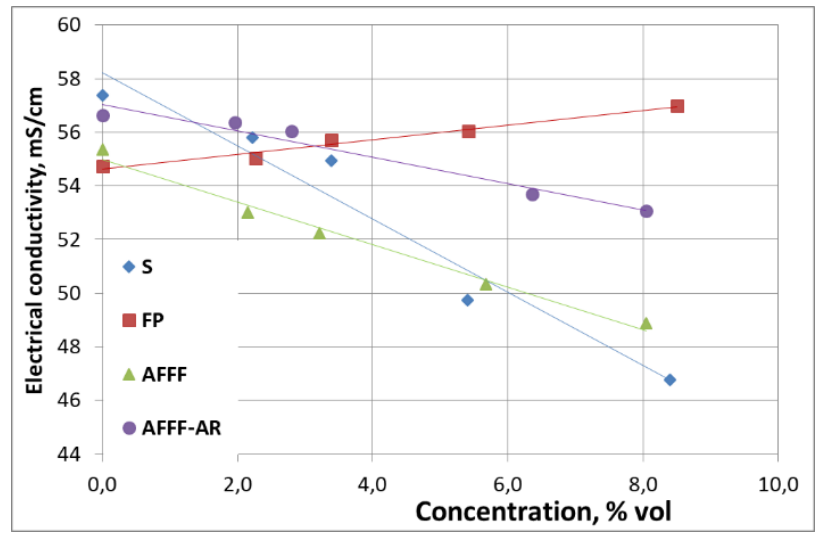

Figure 2. Electrical conductivity of S, AFFF, FP and AFFF-AR foaming agents solutions in saltwater, approx. $35 \mathrm{~g} / \mathrm{dm}^{3} \mathrm{NaCl}, 25^{\circ} \mathrm{C}$.

On the measurement range corresponding to the used saltwater, conductivity meter is much less accurate. In the case of solutions of foaming agents in saltwater expanded 
uncertainty of measurement resulting from the accuracy of the instrument is estimated at $2 \%$ of reading. Solutions of synthetic foaming agents showed a decrease in conductivity compared to water output, only in the case of the FP followed by a small increase in the conductivity of the solutions. The decrease in conductivity of the water shows to the interaction of the ingredients of foam-forming solution with $\mathrm{NaCl}$, which was particularly evident in the case of synthetics solutions.

A significant increase in the electrical conductivity of water resulted in a significant change in the nature depending on the concentration - the electrical conductivity of the solution as compared to tap water.

Table 2 shows also the parameters characterizing the conductivity method for determining the concentration of foaming agents in the solutions in saltwater with electric conductivity approx. $056 \mathrm{mS} / \mathrm{cm}$ by using a conductivity meter CPC 551.

Table 1. Characteristics of conductivity methods for tap water and saltwater

\begin{tabular}{|c|c|c|c|c|c|c|c|c|}
\hline \multirow{3}{*}{$\begin{array}{c}\text { Foaming } \\
\text { agents }\end{array}$} & \multicolumn{2}{|c|}{$\mathrm{dP} / \mathrm{dc}$} & \multicolumn{2}{|c|}{$\begin{array}{l}\text { The linear } \\
\text { correlation } \\
\text { (coefficient R2) }\end{array}$} & \multicolumn{2}{|c|}{$\begin{array}{c}\text { Measurement } \\
\text { uncertainty for 3\% }\end{array}$} & \multicolumn{2}{|c|}{$\begin{array}{l}\text { Reading concentration } \\
\text { uncertainty }\end{array}$} \\
\hline & \multicolumn{2}{|c|}{$\mathrm{mS} / \mathrm{cm} / \%$} & \multicolumn{2}{|c|}{-} & \multicolumn{2}{|c|}{$\mathrm{mS} / \mathrm{cm}$} & \multicolumn{2}{|c|}{$\% \mathrm{v} / \mathrm{v}$} \\
\hline & $\begin{array}{l}\text { tap } \\
\text { water }\end{array}$ & saltwater & $\begin{array}{c}\text { tap } \\
\text { water }\end{array}$ & saltwater & $\begin{array}{l}\text { tap } \\
\text { water }\end{array}$ & saltwater & tap water & saltwater \\
\hline$S$ & 0,22 & $-1,37$ & 0,998 & 0,948 & $\pm 0,013$ & $\pm 1,08$ & $\pm 0,06$ & $\pm 0,8$ \\
\hline AFFF & 0,08 & $-0,79$ & 0,997 & 0,986 & $\pm 0,009$ & $\pm 1,04$ & $\pm 0,11$ & $\pm 1,3$ \\
\hline AFFF-AR & 0,24 & $-0,49$ & 0,997 & 0,960 & $\pm 0,014$ & $\pm 1,11$ & $\pm 0,06$ & $\pm 2,3$ \\
\hline FP & 1,63 & 0,27 & 0,998 & 0,973 & $\pm 0,06$ & $\pm 1,11$ & $\pm 0,04$ & $\pm 4,1$ \\
\hline
\end{tabular}

\subsection{The use of measurements of the refractive index of tap water and saltwater portable refractometer without temperature stabilization}

Digital refractometer Refracto 30GS used to measure refractive index $\mathrm{nD}$ provides accordance with the manufacturer accuracy of \pm 0.0005 in terms of measuring coefficient of $1.3200 \div 1.6500$ at 0.0001 resolution. Measurements were carried out for the same solutions of foaming agents $\mathrm{S}, \mathrm{AFFF}, \mathrm{AR}-\mathrm{AFFF}$ and FP, which measured conductivity. This instrument does have temperature stabilization, and does not compensate for changes in temperature of the sample. The measurements were carried out for thermostatic solutions at $20^{\circ} \mathrm{C}$, in a room at $20 \pm 2^{\circ} \mathrm{C}$ [10]. The results of measurements of the refractive index for the solutions of foaming agents in tap water is shown in Figure 3.

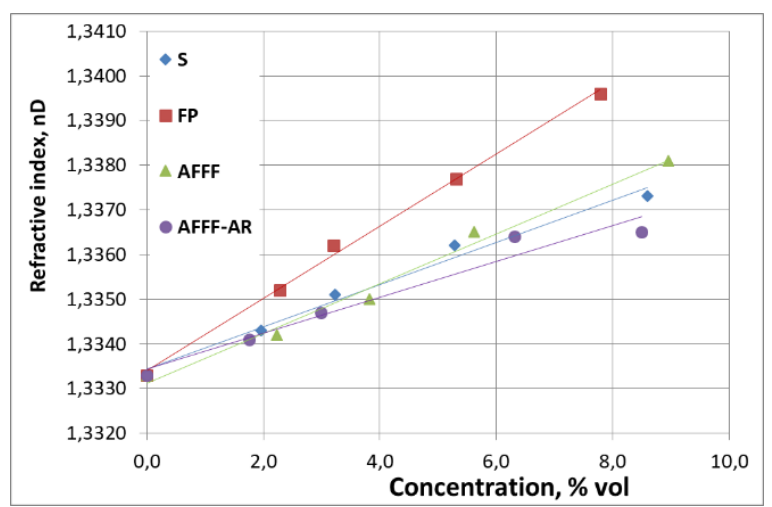

Figure 3. Refractive index of S, AFFF, FP and AFFF-AR foaming agents solutions in tap water, $20 \pm 2^{\circ} \mathrm{C}$. 
The relationship of the refractive index of the foaming agent concentration are linear, but the correlation coefficient is lower compared with the conductivity method for tap water solutions. However, the main problem in this case is too small value of the slope $\mathrm{dP} / \mathrm{dc}$ compared with the measurement uncertainty, which results in large uncertainties reading off the concentration as shown in Table 2.

Relatively high uncertainty of measurement device 30 Refracto GS due to lack of temperature control of the measuring prism and a low volume of the solution in the measuring system. On the other hand advantage of the refractometric method is based on small differences in the course of the calibration relationship and slope $\mathrm{dP} / \mathrm{dc}$ for individual measures and low impact water salinity, as follows from Figure 4, which shows the results of measurements of the refractive index of solutions made of highly saline water.

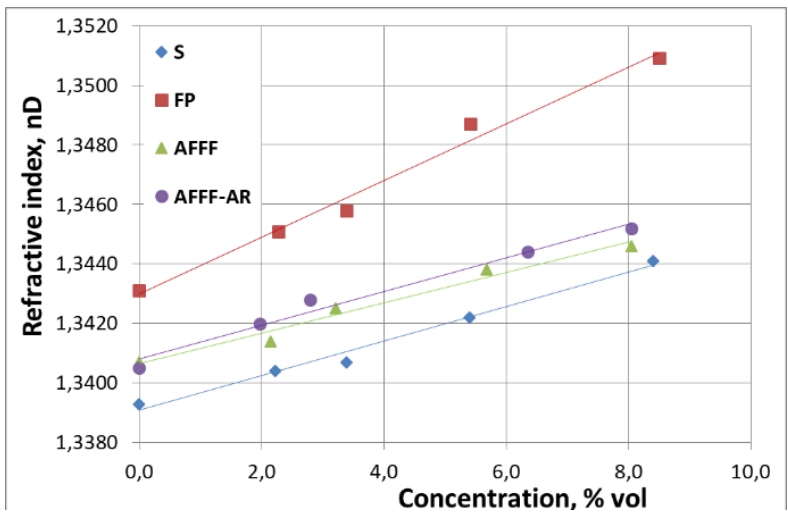

Figure 4. Refractive index of S, AFFF, FP and AFFF-AR foaming agents solutions in saltwater approx. $35 \mathrm{~g} / \mathrm{dm}^{3} \mathrm{NaCl}, 20 \pm 2^{\circ} \mathrm{C}$.

In contrast to the conductivity method character of the relationship does not change, and the obtained value of $\mathrm{dP} / \mathrm{dc}$ and the correlation coefficients are even slightly higher than for tap water as shown in Table 2.

Table 2. Characteristics of the refractometric method without temperature stabilization for tap water and saltwater

\begin{tabular}{|l|c|c|c|c|c|c|c|c|}
\hline \multirow{2}{*}{$\begin{array}{c}\text { Foaming } \\
\text { agents }\end{array}$} & \multicolumn{2}{|c|}{$\mathrm{dP} / \mathrm{dc}$} & \multicolumn{2}{c|}{$\begin{array}{c}\text { The linear } \\
\text { correlation } \\
\text { coefficient R2) }\end{array}$} & \multicolumn{2}{c|}{$\begin{array}{c}\text { Measurement } \\
\text { uncertainty for } 3 \%\end{array}$} & \multicolumn{2}{c|}{$\begin{array}{c}\text { Reading } \\
\text { concentration } \\
\text { uncertainty }\end{array}$} \\
\cline { 2 - 10 } & \multicolumn{2}{|c|}{$\mathrm{nD} / \%$} & \multicolumn{2}{|c|}{-} & \multicolumn{2}{c|}{$\mathrm{nD}$} & \multicolumn{2}{c|}{$\% \mathrm{v} / \mathrm{v}$} \\
\cline { 2 - 10 } & tap water & saltwater & $\begin{array}{c}\text { tap } \\
\text { water }\end{array}$ & $\begin{array}{c}\text { saltwa } \\
\text { ter }\end{array}$ & $\begin{array}{c}\text { tap } \\
\text { water }\end{array}$ & saltwater & $\begin{array}{c}\text { tap } \\
\text { water }\end{array}$ & $\begin{array}{c}\text { saltwa } \\
\text { ter }\end{array}$ \\
\hline S & 0,000473 & 0,000578 & 0,984 & 0,986 & $\pm 0,0005$ & $\pm 0,0005$ & $\pm 1,06$ & $\pm 0,86$ \\
\hline AFFF & 0,000556 & 0,000512 & 0,987 & 0,986 & $\pm 0,0005$ & $\pm 0,0005$ & $\pm 0,90$ & $\pm 0,98$ \\
\hline AFFF-AR & 0,000402 & 0,000564 & 0,959 & 0,975 & $\pm 0,0005$ & $\pm 0,0005$ & $\pm 1,24$ & $\pm 0,89$ \\
\hline FP & 0,000807 & 0,000949 & 0,997 & 0,986 & $\pm 0,0005$ & $\pm 0,0005$ & $\pm 0,62$ & $\pm 0,53$ \\
\hline
\end{tabular}

Analysis to the relationship of the concentration of foaming agent - the refractive index and the parameters included in Table 2 leads to the conclusion that the refractometric method could be an alternative to the method of conductivity, especially in the case of water with high electrical conductivity. However, to solve the problem of uncertainty of measurement that can be achieved by temperature stabilization the measurement system. 


\subsection{The use of measurements of the refractive index refractometer with temperature stabilization}

Temperature stabilization of the measuring system can be realized by using an external thermostat, which in practice excludes or very difficult to perform measurements outside the laboratory, or by using an integrated system with thermostatic Peltier device. In the case of a digital refractometer RA 620 Kyoto Electronics temperature stabilization of the sample solution to the accuracy of $0,01^{\circ} \mathrm{C}$ provides a measurement resolution $0.00001 \mathrm{nD}$ and accuracy of $0.00002 \mathrm{nD}$.

Figure 5 shows the results of measurements made by refractometer RA 620 for the solutions of S and AFFF (other than the above-presented research), prepared from water with a higher electrical conductivity [10].

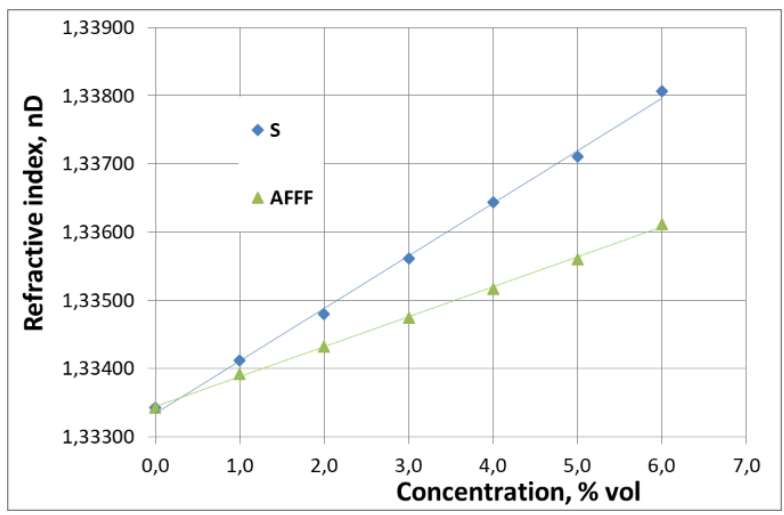

Figure 5. Refractive index of $\mathrm{S}$ and $\mathrm{AFFF}$ foaming agents solutions in water with electric conductivity approx. $0.6 \mathrm{mS} / \mathrm{cm}, 20 \pm 0,01^{\circ} \mathrm{C}$

Temperature stabilization measuring system with high accuracy provides a very good reproducibility of results and high measurement accuracy. Concentration reading from the graphs of calibration relationship can be performed with high accuracy, as shown in Table 3 .

Table 3. Characteristics of the refractometric method with thermostatic Peltier device for water with electric conductivity approx. $0.6 \mathrm{mS} / \mathrm{cm}$

\begin{tabular}{|l|c|c|c|c|}
\hline \multirow{2}{*}{$\begin{array}{c}\text { Foaming } \\
\text { agents }\end{array}$} & $\mathrm{dP} / \mathrm{dc}$ & $\begin{array}{c}\text { The linear correlation } \\
\text { (coefficient } \mathrm{R}^{2} \text { ) }\end{array}$ & $\begin{array}{c}\text { Measurement } \\
\text { uncertainty for 3\% }\end{array}$ & $\begin{array}{c}\text { Reading concentration } \\
\text { uncertainty }\end{array}$ \\
\cline { 2 - 5 } & $\mathrm{nD} / \%$ & - & $\mathrm{nD}$ & $\% \mathrm{v} / \mathrm{v}$ \\
\hline $\mathrm{S}$ & 0,000769 & 0,998 & $\pm 0,00002$ & $\pm 0,03$ \\
\hline AFFF & 0,000439 & 0,999 & $\pm 0,00002$ & $\pm 0,05$ \\
\hline
\end{tabular}

Use of the refractometer measurement with temperature stabilization system allows the use of a refractometric method to accurate measurement of all types of foaming agents in solutions with different electrical conductivity. Influence of the type of water is much smaller than the conductivity method. However, same as in case of conductivity method, it is necessary to determine the calibration relationship for solutions made up of the same water and the same means as those used for the preparation of the solution of unknown concentration. 


\section{Summary}

The research found that the conductivity method can be used to determine the actual concentrations of all types of foaming agents in the solutions made from tap water, or water of similar electrical conductivity, of approx. $0.5 \div 0.8 \mathrm{mS} / \mathrm{cm}$. Conductivity meter must be equipped with temperature compensation system. Measurement uncertainty is estimated to be \pm 0.1 vol. $\%$ under optimal conditions for this method. With an increase in the conductivity of water conductivity measurement uncertainty of the concentration of foaming agents is increasing rapidly, even using an accurate laboratory equipment. In practice, if the electrical conductivity of water exceeds approx. $2 \mathrm{mS} / \mathrm{cm}$, measurements of the concentration of AFFF solution cannot be perform by portable conductivity meter with sufficient accuracy.

In all cases, the applicability of the conductivity method and in the case of water with high electrical conductivity also refractometric method gives good results. In the case of solutions made with tap water and foaming agents working concentrations of $3 \%$ and more acceptable uncertainty in the measurements provides portable digital refractometer without temperature stabilization. In other cases, obtaining sufficient accuracy requires sample temperature stabilization during the test. In a study conducted as part of this work also the laboratory refractometer with Peltier temperature stabilization system was used and a concentration measurement uncertainty of less than $\pm 0.1 \%$ was given.

\section{References}

1. A. Mizerski, M. Sobolewski, B. Król, Hasicí pěny, SPBI (2009)

2. PN-EN 1568-3

3. PN-EN 1568-4

4. PN-EN 13565

5. PN-EN 13565-1+A1: 2010

6. Rozporządzenie Ministra Spraw Wewnętrznych i Administracji z dnia 27 kwietnia 2010 (Dz. U. $2010 \mathrm{nr} 85$ poz. 553)

7. G. Timms, P.Haggar, Fire Technol. 2, 41 (1990)

8. PN-ISO 15705: 2005

9. B. Król, A. Mizerski, A. Sewastianowicz, M. Sobolewski, Zeszyty Naukowe SGSP, 30, 5 (2003)

10. Project Report S/E-422/22/14 Development of new methods for measuring the actual concentration of foaming agents in foam systems (SGSP, Warszawa 2015) 